\title{
Built Environment and Elderly Population Health: A Comprehensive Literature Review
}

\author{
Noe Garin ${ }^{1,2,3}$, Beatriz Olaya ${ }^{1,2,3}$, Marta Miret ${ }^{3,4,5}$, Jose Luis Ayuso-Mateos ${ }^{3,4,5}$, Michael Power ${ }^{6}$, \\ Paola Bucciarelli ${ }^{7}$ and Josep Maria Haro ${ }^{1,2,3,{ }^{*}}$
}

\begin{abstract}
${ }^{I}$ Parc Sanitari Sant Joan de Déu, Universitat de Barcelona. Dr Antoni Pujades, 42, 08830, Sant Boi de Llobregat, Barcelona, Spain; ${ }^{2}$ Fundació Sant Joan de Déu. Santa Rosa, 39-57, 08950. Esplugues de Llobregat, Barcelona, Spain; ${ }^{3}$ Instituto de Salud Carlos III, Centro de Investigación Biomédica en Red de Salud Mental, CIBERSAM. Monforte de Lemos 3-5. Pabellón 11. 28029 Madrid, Spain; ${ }^{4}$ Department of Psychiatry, Universidad Autónoma de Madrid. Arzobispo Morcillo s/n 28029 Madrid, Spain; ${ }^{5}$ Department of Psychiatry, Hospital Universitario de La Princesa, Instituto de Investigación Sanitaria Princesa (IP). Diego de León, 62, 28006. Madrid, Spain; ${ }^{6}$ Instituto de Salud Carlos III; ${ }^{6}$ Department of Clinical Psychology, School of Health in Social Science, University of Edinburgh, Edinburgh EH8 $9 A G$, UK; ${ }^{7}$ Scientific Directorate, Neurological Institute Carlo Besta, Milan, Via Celoria 11, Italy
\end{abstract}

\begin{abstract}
Global population aging over recent years has been linked to poorer health outcomes and higher healthcare expenditure. Policies focusing on healthy aging are currently being developed but a complete understanding of health determinants is needed to guide these efforts. The built environment and other external factors have been added to the International Classification of Functioning as important determinants of health and disability. Although the relationship between the built environment and health has been widely examined in working age adults, research focusing on elderly people is relatively recent. In this review, we provide a comprehensive synthesis of the evidence on the built environment and health in the elderly.
\end{abstract}

Keywords: Built environment, elderly people, literature review, mental health, physical health, quality of life, well-being.

\section{INTRODUCTION}

The increase in life expectancy over recent decades has led to considerable population ageing, a global process that especially affects Western countries. A 2-fold increase in population over 60 years is expected from 2006 to 2050 , when it is believed that the number of elderly people will exceed the population aged under 14 years worldwide [1]. There is a clear relationship between ageing and morbidity, mortality, disability, perceived quality of life and health expenditures [2-9].

Policies regarding population ageing focus on various health determinants, among which housing and the built environment have become important actors [10-13]. As a health determinant, the built environment is a broad term which encompasses buildings, spaces, and products that are created or modified by people [14]. Several theories have been proposed to explain the link between environment and physical activity, such as travel behavior theory, environmental press theory, social learning theory, ecological theory and behavior setting theory [15]. The ecological model described by Stockols in the context of Healthy Environments is a broad framework which takes into account the physical

*Address correspondence to this author at the Parc Sanitari Sant Joan de Déu, Universitat de Barcelona. Dr Antoni Pujades, 42, 08830, Sant Boi de Llobregat, Barcelona, Spain; Tel: +34 936406350; Fax: +34 935569674;

E-mail: jmharo@pssjd.org environment and the psychosocial environment [16]. This model highlights the functional links between the aging person and micro-, meso-, and macrosystem levels of the environment, as well as the unstable equilibrium between environment and individual competence in very old age [17]. However, the built environment is not only related to health through physical activity. It is also connected to health through other aspects: falls, pollution, social interaction, safety, economical and climate issues [18-21]. Moreover, the effect of the built environment on elderly people in particular has to be taken into account, as this population tends to spend more time at home and in the community area compared with other age groups [22].

The relationship between the built environment and health has been widely studied during recent years in the general population, focusing on how the built environment impacts a wide range of issues including obesity, physical activity, general health, birth outcomes, mental illness or morbidity [23-32]. Therefore, The International Classification of Functioning, Disability and Health (ICF) has incorporated environmental factors as determinants of health and disability [33].

Reviews focusing on the built environment and health outcomes have been mainly focused on adult population and there is little information about the effect of the built environment on elderly people, especially in community residents [34]. This is especially relevant as the elderly suffer from high morbidity and disability rates. In addition, most 
information available is focused on the impact on physical activity, whilst other aspects of physical health, mental health and quality of life need to be addressed. It is important to elucidate this association in general population, excluding special care and nursing home which should be analyzed separately. Moreover, reviews have included outcomes referring to both physical and sociocognitive factors, as well as methodological variations and incompleteness in method reporting, so that it is difficult to assess their results [35].

The aim of this review is to summarize the evidence on the built environment and health in the non-dependant community-residing elderly through a review of the literature published over the last 10 years. This review focuses on four aspects:

1) Built environment \& Physical health.

2) Built environment \& Mental health.

3) Built environment $\&$ Life satisfaction variables

4) Study methodologies used in assessing the built environment.

\section{METHODS}

A systematic review through computer searches of Pubmed and ISI Web of Science were conducted to identify English language studies. Both sources involve a wide range of databases (PubMed, Web of Science ${ }^{\mathrm{TM}}$ Core Collection, Current Contents Connect ${ }^{\mathbb{B}}$, Derwent Innovations Index ${ }^{\mathbb{B}}$, MEDLINE) which are complementary to get the most relevant papers on this topic. Since the interest for the built environment has grown exponentially over the last years, the search was limited to the last decade (January 2002- December 2012) and then updated to September 2013. Search terms were grouped into three categories: aging (aging, older people, elderly people), built environment (built environment, housing, capacity of building), and health outcomes (health, wellness, wellbeing, disability, quality of life, comorbidity, functional limitations, disabled persons, mentally disabled persons) (Fig. 1).

Search procedures were implemented to obtain the best possible evidence. Duplicates were deleted. Abstracts were selected for further examination where they met criteria and then full article was reviewed to determine whether it was suitable for inclusion. Selection criteria were:

- Age selection criteria: study population groups of individuals over 50 years and studies with specific analysis of people aged over 50 years. Studies with other age selection criteria but reporting on a mean age over 55 years were also included.

- Articles focusing on the effect of economical or psychosocial circumstances (e.g. housing tenure, security, welfare benefits) on health outcomes were excluded.

- Articles including dependent population and elderly people living in institutions or housing for the elderly (e.g. retirement community) were excluded, as people in these situations were considered to live in adapted communities with special care, which would require a specific analysis depending on the patient needs.

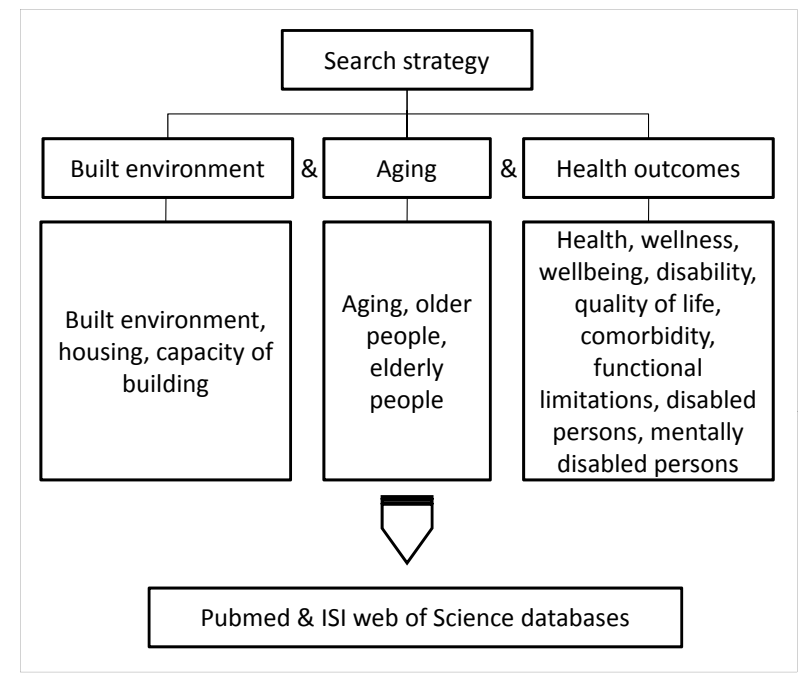

Fig. (1). Search strategy summary with keywords.

Non original articles, qualitative studies and reviews were initially excluded. However, text reviews of these articles were used to identify additional articles. Additional assessment of all the introductions and discussions regarding all the selected original articles was performed to maximize the volume of articles meeting our inclusion criteria. In order to summarize the results of the search, studies were sorted by the following groups: 1) physical health; 2) mental health and 3) a combined group including concepts related with life satisfaction (quality of life, wellbeing, successful ageing, and healthy ageing).

\section{RESULTS AND DISCUSSIONS}

By using the established criteria, we found 48 articles focusing on the relationship between aging, the built environment and health. The results of the search are summarized in Fig. (2).

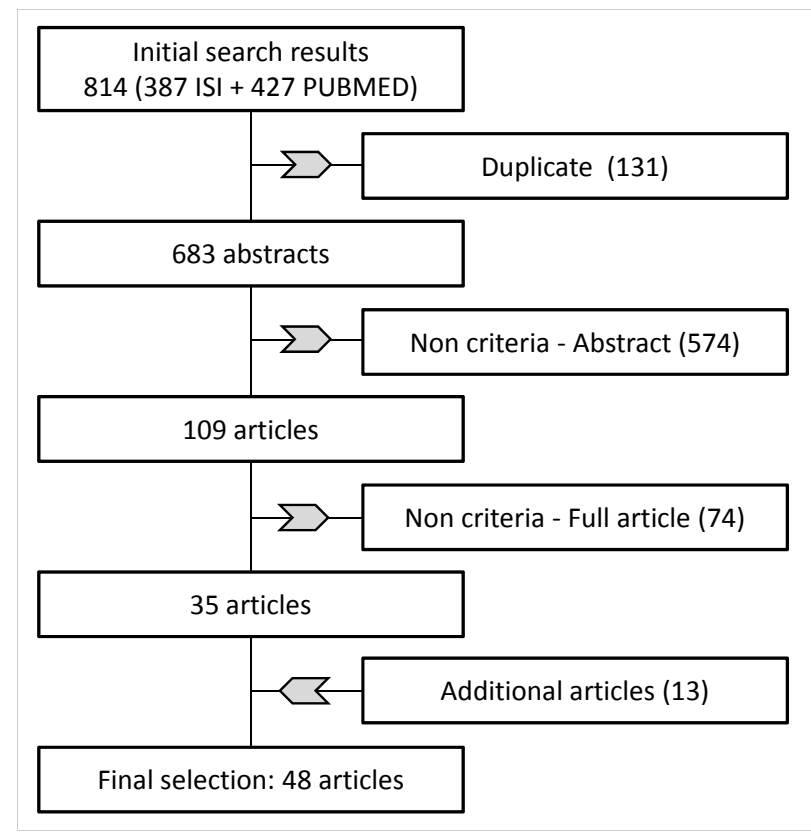

Fig. (2). Methodological proceedings and results of the search. 
The results and discussions of evidence found in the selected studies are categorized under the following major headings: a) physical health; b) mental health; c) life satisfaction.

\subsection{Physical Health}

Most of the selected studies assessed physical health $(\mathrm{n}=34)$, taken as a broad term including preventive care, functioning and disability, injuries and other health-related conditions (e.g. perceived health, hypertension, arthritis symptoms, mortality) (Table 1).

Seven studies focused on the relationship between the built environment and injuries [36-42]. The approach in these studies was through examination of distinct variables, e.g. falls, home injuries, home hazards and hip-fracture risk. All of the studies linked at least one built environment variable (built environment variable) with this issue. For example, Dogan et al. (2005) found an association between bathing facilities and home injuries [38]. The built environment variables associated with injuries included mainly housing issues. Similar results were observed in the seven articles focusing on disability or functioning [14, 43-48]. In that case, outdoor built environment variables such as connectivity, excessive noise, inadequate lightning or street condition were related to disability [14, 43, 47]. Preventive health was assessed through vaccination, preventive health care and use of dental service in three studies [33, 49, 50]. No evidence supporting a relationship between preventive health care and the built environment was found. The association between built environment and mortality was associated in three studies. For example, one study found that the presence of parks, tree lined streets and space for taking strolls was associated with higher five-year survival [51]. At an indoor level, differences were found in the other two studies, in which variables related to temperature, such as feeling cold or lack of thermal insulation, were associated with mortality $[52,53]$. Other associations between physical health and built environment found in the selected studies included selfrate health, comorbidity, arthritis symptoms, hip fracture risk, hypertension and asthma [54-67].

Studies on physical health have some specific limitations. First of all the variety of variables and definitions used, which difficult comparison between studies. Moreover, reduced capacity may affect walking activity and could lead to a different perception of the neighborhood, which may skew the results $[62,68]$. Furthermore, there could be a bias caused by the possibility that active elderly people may choose to live in more-walkable neighborhoods [62, 69-71]. In addition to the direct effect on physical functioning, environment may also influence social support and psychological distress, and this can also impact physical functioning. One study found a significant association between the presence of variables that are thought to promote social contacts (more front porches, stoops and buildings built above grade) and physical functioning, but this model requires further investigation [71].

The built environment has been shown to impact on physical health at different levels. It has been previously stated that the built environment can limit or promote the ability to complete specific actions [72]. A better physical functioning may be related to some of the physical health results, especially taking into account the nature of some built environment variables such as walkability and connectivity. Other specific variables would be related to specific domains, e.g. indoor issues and injuries, temperature concerns and mortality [73]. A model including built environment enlarges the medical model that typically focuses on the individual and pathology connecting the person with the environment [74]. Our results support the review by Cunningham \& Michael (2004), which concluded that environmental factors should be taken into account rather than concentrating solely on specific efforts to promote physical activity [15]. However, there is need to foster the knowledge of specific environmental variables on health outcomes such as injuries, disability and chronic conditions. In addition, various approaches are needed to assess the indirect role of the built environment in physical health through variables such as social support or psychological distress [71].

\subsection{Mental Health}

Mental disorders are common in elderly people, reaching $20 \%$ prevalence in those without dementia aged 65 years and older [75]. However, most research on the built environment has focused on physical health compared with the research regarding mental health $[26,76,77]$. In the elderly, the immediate urban environment becomes an important issue. People tend to spend more time in this environment because of physical decline, retirement, decreased access to transport and shrinking in social networks. Psychosocial processes related to these features would be connected to mental health in several ways $[78,79]$.

Only eight studies were found to assess mental health, of which five assessed the influence on depression (Table 2) [80-84]. Depression prevalence was linked to the number of rooms in the house, satisfaction with housing, housing quality, land-use mix and retail availability, whilst no relation was found regarding residential density, street connectivity, and walkability. For example, Lai \& Guo (2012) found that satisfaction with housing was associated with fewer depressive symptoms [81]. One study examining psychological distress and another one assessing positive affect did not find any link between the built environment and these variables [85, 86]. Finally, Howden-Chapman et al. (2011) found a direct relationship between housing quality problems (including home size, need of repairs and presence of moisture) and minor psychiatric morbidity measured with the General Health Questionnaire (GHQ-30) [78].

Among these studies, methodological difficulties were found regarding the variability of the assessed variables and the differences in the definitions of mental and environmental variables. For instance, housing quality was assessed in three studies through three different methods $[78,83,85]$. On the other hand, some environmental variables that were previously suggested as mental health mediators, including floor level, noise or indoor air quality, were not assessed in these studies [85]. Another interesting issue to consider in future studies is the possibility that people moving to certain areas may have higher social skills, so that the results can be biased [87]. Furthermore, there might be variables which lack reliability as they were developed specifically for the 
Table 1. Details of reviewed articles of physical health, preventive healthcare and the built environment.

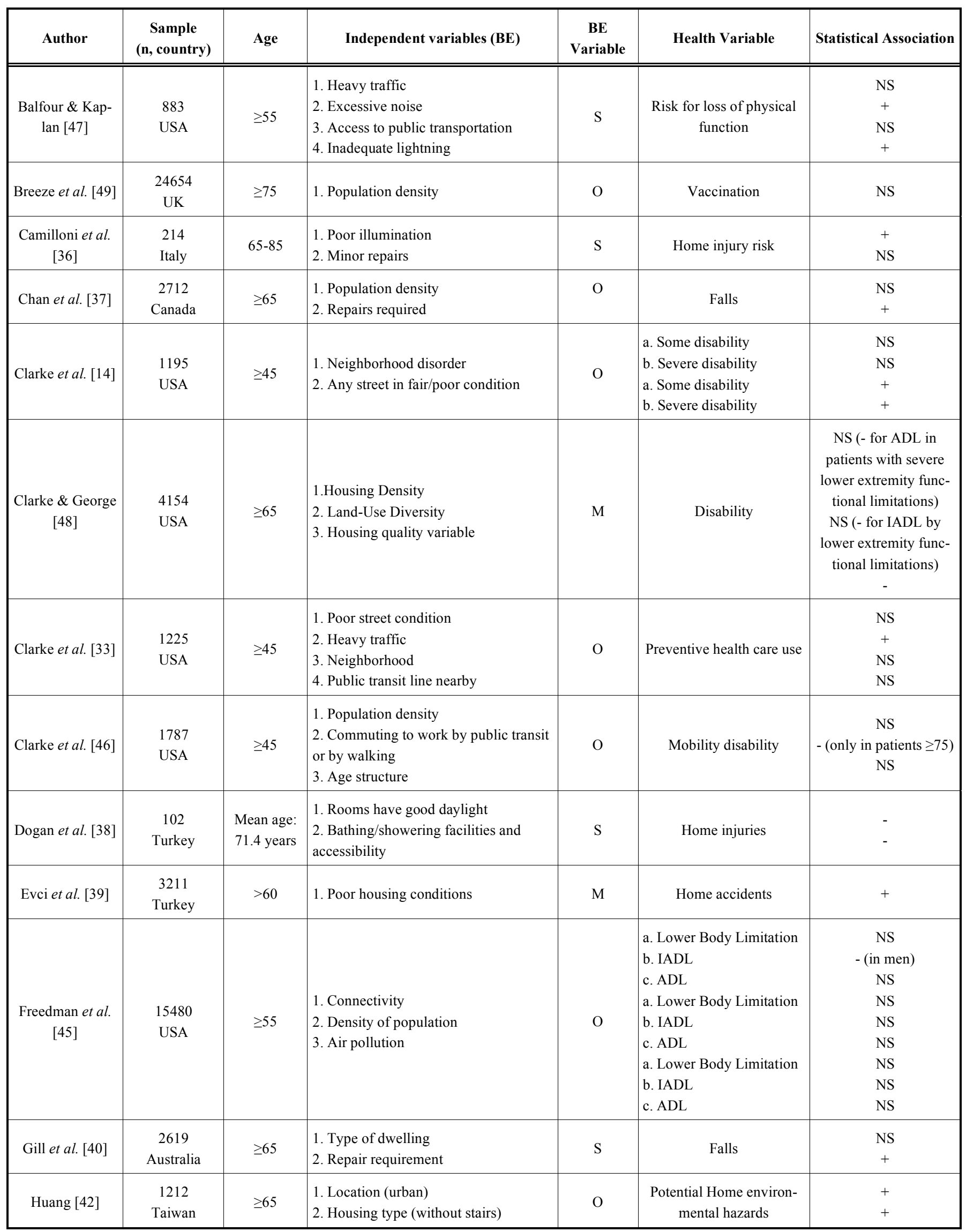


(Table 1) contd....

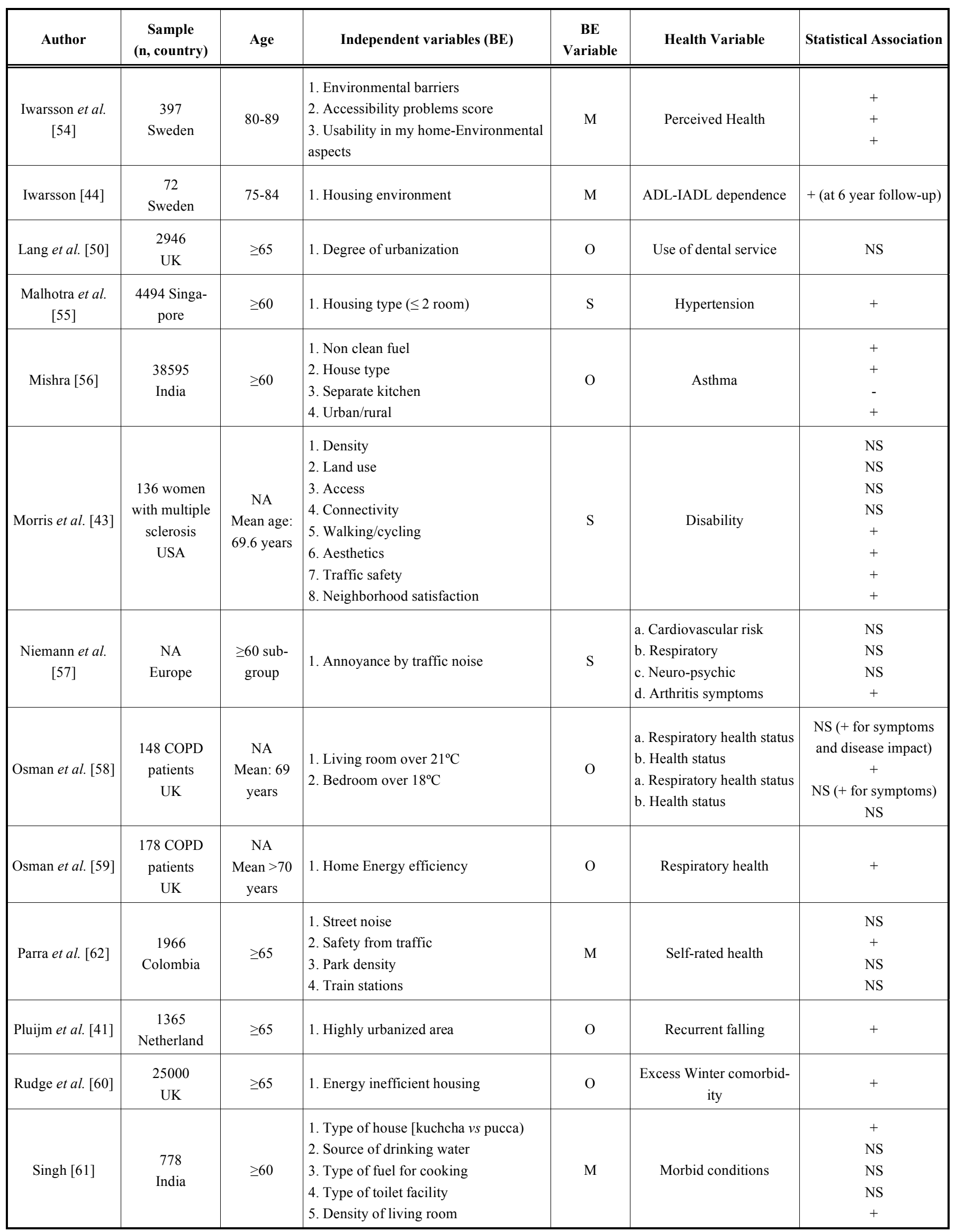


(Table 1) contd....

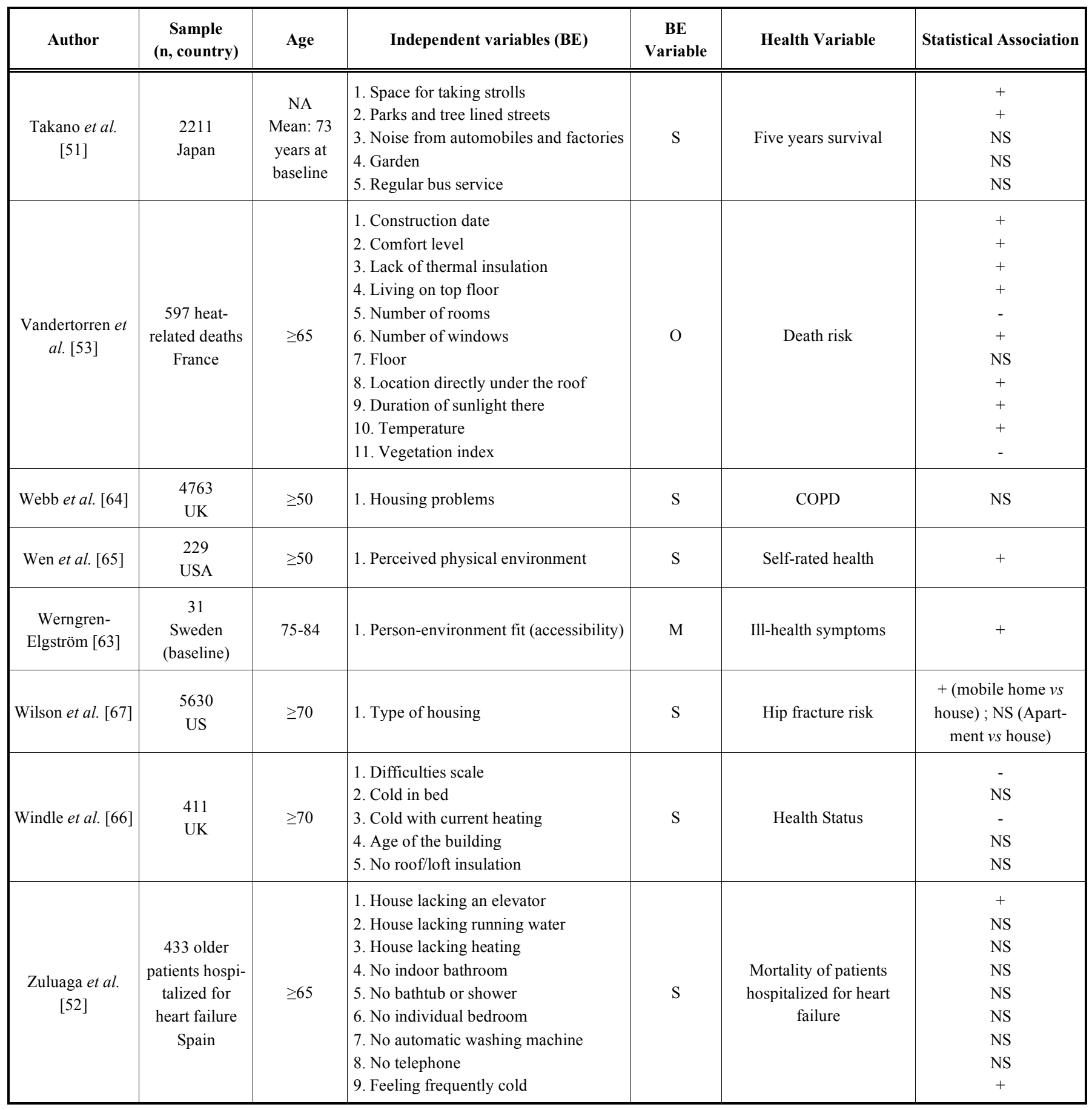

(+) Statistically significant, positive effect on outcome; (-) Statistically significant, negative effect on outcome; (NS) Not statistically significant; (O) Objective measure of BE; (S) Self-rated measure of BE; (M) Mixed measure, including objective and self-rate; (NA) Data not available; (COPD) chronic obstructive pulmonary disease; (ADL) activities of daily living; (IADL) instrumental activities of daily living.

study and were in some cases confined to a dichotomous answer. Data on confounders such as physical exercise should also be measured in the studies [82, 88, 89].

The effect of the built environment on mental health becomes a delicate issue since it may be difficult to elucidate the effects of physical and social environment [90]. For example, open spaces could lead to social interaction and physical activity which can be linked to individual perceptions, unmet needs and mental health [91]. In fact, it is diffi- cult to separate physical influences from other environmental influences: institutional factors, community factors, policy [92]. However, independent effects on health due to certain environmental factors have been settled in previous studies and further research is needed to promote the more suitable environment for mental health [76].

Most of the evidence found in this review has focused on depression, which has been clearly associated with some environmental variables. Little evidence has been found in 
Table 2. Details of reviewed articles of mental conditions and the built environment.

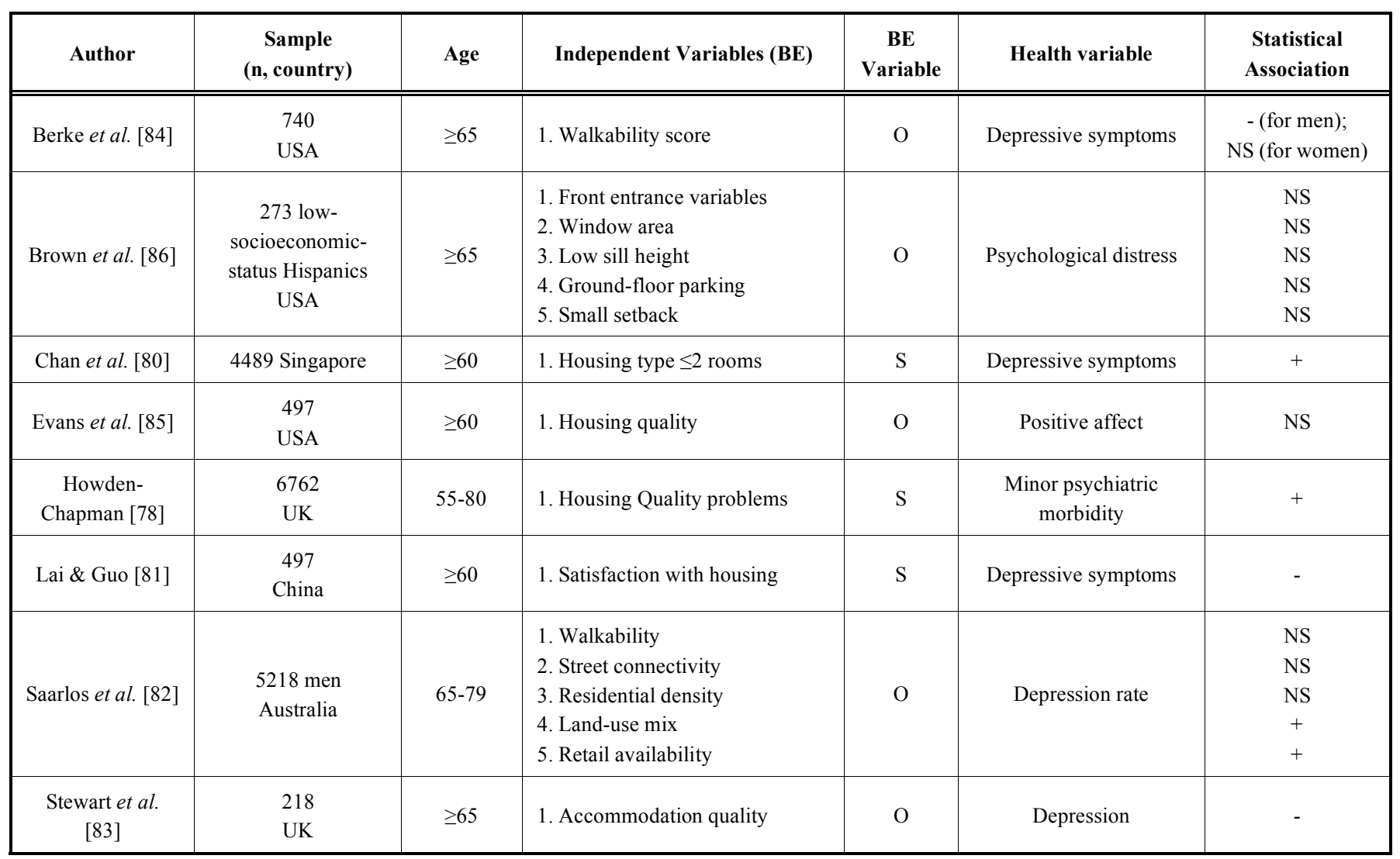

(+) Statistically significant, positive effect on outcome; (-) Statistically significant, negative effect on outcome; (NS) Not statistically significant; (O) Objective measure of BE; (S) Self-rated measure of BE; (M) Mixed measure, including objective and self-rate.

other variables such as positive affect, psychological distress and minor psychiatric morbidity. More research is necessary to establish more precise interaction with mental health, especially in conditions others than depression.

\subsection{Life Satisfaction and Related Variables}

Quality of life (QOL) is a broad multidimensional concept that usually includes subjective evaluations of both positive and negative aspects of life, whilst well-being is defined as a category of phenomena that reflects satisfaction with various domains of life, global judgments of life satisfaction, and current affective state [93, 94]. The WHO has considered the enhancement of quality of life as a major issue in ageing, leading to an increased interest in the relationship with the built environment in recent years $[12,95]$.

Ten studies focused on quality of life, well-being and related concepts such as life satisfaction or successful aging [33, 54, 62, 63, 96-101] (Table 3). Among these studies, several distinct environment variables were used, so that a broad analysis was not possible. However, it is noticeable that the Housing Enabler was used as the instrument for assessing accessibility in three of the studies [54, 63, 96]. Two of the studies using this instrument found a link between accessibility and both life satisfaction and healthy aging, whilst the study by Werngren-Elgström et al. (2009) did not find a relationship with subjective well-being [63]. Accessibility was also assessed in another study and showed no effect on life satisfaction for most of the built environment variables [97].
Apart from accessibility, other variables were significantly associated with health outcomes. For example, variables such as residential satisfaction, home size, housing type, heavy traffic, higher usability, exterior environment, interior environment, street noise and safety from traffic were associated with quality of life, well-being, life satisfaction or successful aging [33, 54, 62, 96-100]. However, the following variables were not connected with life satisfaction, well-being and quality of life: urbanicity (urban/rural), poor street condition, public transit line nearby, park density, number of train stations, housing comfort, number of rooms, environmental barriers, housing satisfaction and neighborhood quality [33, 54, 62, 96, 97, 101].

As observed in the previous health domains but especially in this case, there is a high degree of variability in methodology and results. The fact that almost every study focused on different environmental variables or similar variables with a different approach makes it difficult to hypothesize on the nature of the relationship. Several models connecting environmental factors and quality of life have emerged in recent years. Sugiyama \& Thompson (2007) proposed four different models. One model states that environmental factors may be a proximal predictor of quality of life [91]. In contrast, the other models involve indirect associations through outdoor activity, personal factors, personal projects and unmet needs. All these issues suggest the need for further research into the model so that studies could focus on the factors with the greatest impact on quality of life. 
Table 3. Details of reviewed articles of quality of life, well-being, successful aging and the built environment.

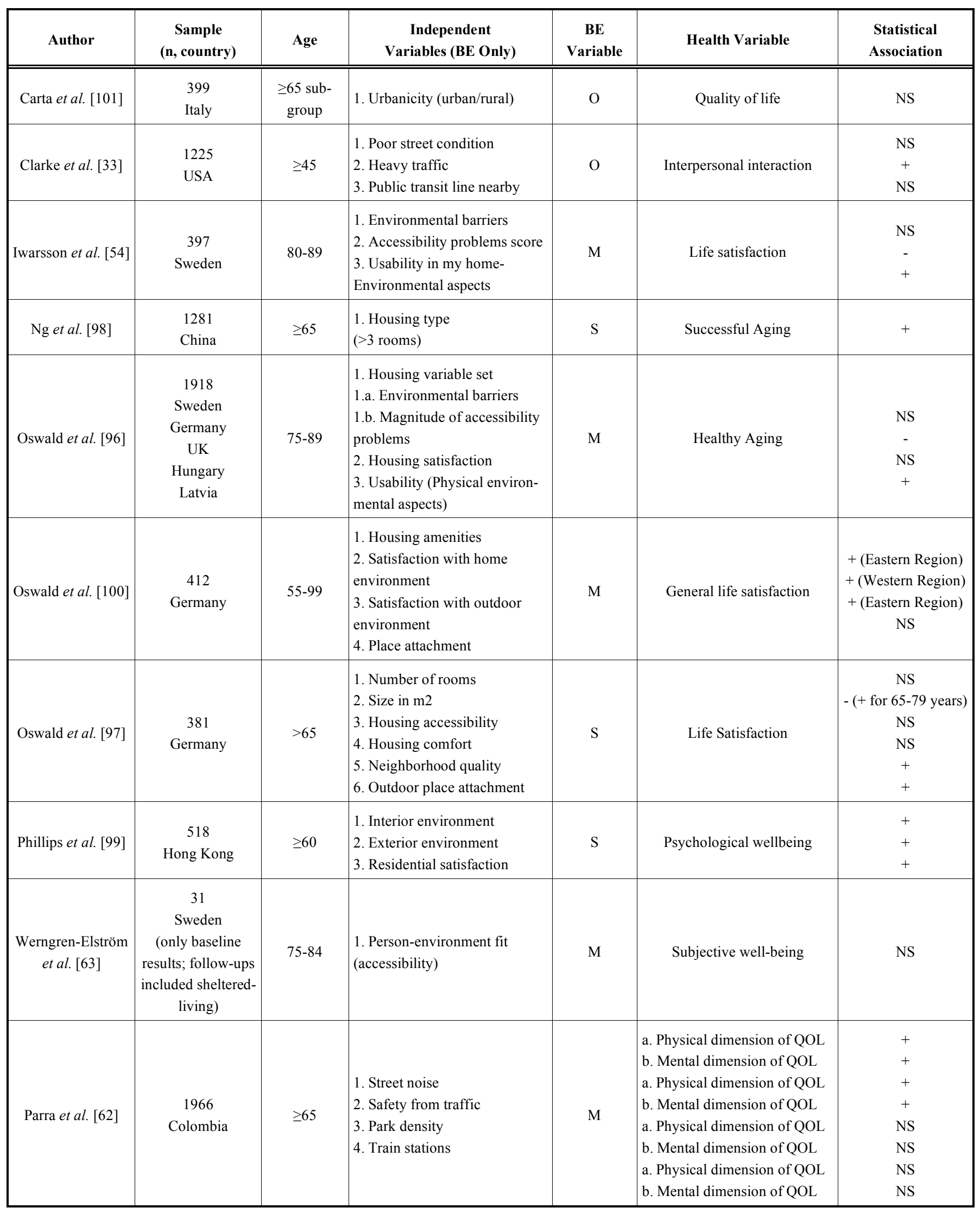

(+) Statistically significant, positive effect on outcome; (-) Statistically significant, negative effect on outcome; (NS) Not statistically significant; (O) Objective measure of BE; (S) Self-rated measure of BE; (M) Mixed measure, including objective and self-rate. 


\subsection{Methodology in Built Environment Research}

Methodological concerns arise in the studies connecting the built environment and health, among which the variety of variables and the lack of constant definitions or measure units are highlighted. According to the type of built environment measure, the articles could be classified as objective (20 papers), self-report (19 papers), mixed studies involving both objective and self-reported measures ( 9 papers).

Two types of objective measures can be distinguished: a) those derived from geographic measures, census tracts or similar databases and b) those from interviewers acting as observers in streets and homes. Several instruments and tools have emerged in recent years for the objective assessment of environmental issues. These instruments produce a single score linking the built environment and health. The following designed tools were found to assess the impact of the built environment on elderly people:

- Walkability index of the Walkable and Bikable Communities Project (WBC) [84]. This index contains data from Geographic Information System (GIS) and public sources about specific items. Circular buffers of 100, 500, and 1000 meters were created around each point.

- University of Miami Built environment coding system UMBECS [86]. It assesses 76 features regarding the built environment, although few of them were finally used in the selected studies: front entrance, window area, low sill height, ground-floor parking, and small setback.

- Systematic social observation system [14,33]. This validated examination is also based on a direct observational method, rating several conditions: curbs, holes, etc.

There are some reservations regarding the use of these instruments. Firstly, the use of a composite variable could fail to take into account individual features that could matter in mental health, physical health or quality of life [82]. Secondly, it may be difficult to compare the results, given that they assess distinct domains of the built environment. Furthermore, there may be interviewer bias, and therefore interviewers should be trained to administer these instruments. Finally, it is important to demonstrate their validity and reliability but only the Systematic Social Observation System and the Walkability index were found to be validated tools, and only for general population $[102,103]$.

Studies with self-reported built-environment variables represent a similar volume of evidence as the group of studies with objective measures. Subjective evaluation has high individual variability so self-report validation is needed to get more accurate results [36]. Among the 19 articles using a subjective measure of the built environment, only one standardized tool was used: the neighborhood environment walking scale - NEWS [43]. The NEWS survey is a validated tool which involves perceptions of nine environmental characteristics at a neighborhood level [104, 105]. However, elderly-based validation is needed [104-106]. The other reported studies using self-rating measures obtained most of the results from five-item Likert scales and dichotomic scales. Self-perception of housing was considered a nonspecific measure in some analyses. This can result in very positive ratings if asking about satisfaction in general terms, so it was considered that reliability would be strengthened by independent measures [54, 78, 97]. Moreover, it is thought that subjective opinions in poorer circumstances could be linked to a negative world view that could lead to more perceived difficulties with regard to housing and severity of illness [66]. Finally, self-report questionnaires for elderly people have to be short and easy to understand, which might hinder the use of some variables due to their complexity [97].

Only 9 studies assessed the built-environment variables through the combination of both objective and self-rated measures, which provides a more comprehensive assessment [43]. This approach aims to reduce the subjectivity of the measurements while keeping the individual perception that could also result in different physical behaviours. In some cases, GIS data might not be representative of the perceived neighborhood. With respect to standardized tools, four studies used the Housing enabler $[44,54,63,96]$. This tool has been validated but there is still a need for it to be validated in the elderly population $[107,108]$. The Housing enabler consists of an initial step to assess functional limitations; combining an interview with direct observation. The second step assesses physical barriers objectively, and then an accessibility score is calculated based on the first two steps $[107,109]$. However, these studies selected different variables from the Housing enabler tool for data analysis.

Built-environment related variables may also be classified according to the space on which the study was focused a) indoor variables, defined as immediate domestic home environment and $b$ ) outdoor variables or neighborhood variables, defined as the immediate out-of-home environment [97]. Both types of variables may be needed since, as stated before, indoor or outdoor variables may be independently linked to specific domains of health. However, as with other issues connected with the built environment research, there is no clear agreement on definitions and a single framework is needed.

Another methodological issue is the type of design used. The information collected from these studies came mainly from cross-sectional data, making the establishment of a causal link methodologically difficult $[80,97]$. Despite data suggesting the effects of the built environment on several health issues, the association cannot be described as beyond doubt, and the few prospective studies have a limited observational period. Only 9 out of the total of 48 papers assessed longitudinal data, among which only four studies had information gathered over five or more years [44, 51, 52, 78]. Furthermore, environments change over time and this situation can also affect the results of cross-sectional data [62]. More longitudinal studies are needed to understand causal and temporal relationships.

Extrapolation of the data to other countries or areas may not be appropriate as many discrepancies regarding housing and urban planning exist between them. Moreover, individual-level information from census and secondary data sets tract often differ from the areas covered on foot compared with a more precise description from individual-level geographical data $[45,46,84]$. There is risk of modifiable areal unit problem (MAUP), scale and aggregation effects resulting in statistical bias [110]. For example, one area scale (e.g, 
census block) can lead to different results when compared with analysis using another scale (e.g., census tracts). Assuming that participants live in the center of the selected area or changing the shape of the aggregate area can also lead to MAUP [82, 84].

It was considered that some of the studies had insufficient group or subgroup size to make strong statistical inferences $[52,54,62,100]$. Some studies had a considerable loss of enrolled participants, a high number of people who refused to participate or participation bias, all of which can lead to misinterpretation of the results $[36,78,101]$. It has been suggested that in some studies, cases were more predisposed than controls to report problems. This could happen, for example, when reporting the risks of accidents at home [36]. Another possible source of bias is the fact that some people may be recent arrivals in a neighborhood and their current health could be affected to a greater extent by their previous place of residence. The same could happen with regard to socioeconomic status [49]. It is important to take into account the influence of several intermediate individual factors, such as family support, baseline health status, health policies or social engagement so that the inferences can be made with confidence that the built environment is the single most relevant factor underlying the results in health $[42,45$, 84].

On some occasions, long-term dwellers were the target of the study, which could be considered positive as they had been living long enough in the area for a possible interaction between the built environment and health to be established. On the other hand, it could lead to reduced potential to detect the problems in cases where subjective variables were used [47].

\subsection{Implications for Health Policy and Future Research}

Ideally, people should not need to move to be in a supportive environment, but there is a need for elder-friendly knowledge, including terms of equity [111]. Historically, policy makers have focused their attention on the study of long-term care, social affairs and health care but the impact of built-environment has rarely been investigated explicitly [112]. The evidence that has arisen during recent years has led to interest in and promotion of age-friendly cities but there is need for policy implementation at a national and local levels [112]. As clear associations are found, urban planning innovation should become a major aim for stakeholders considering expected aging predictions.

There is a need to agree on how to proceed with the builtenvironment assessment, taking a broad approach and unifying theoretical framework to aid understanding [22, 113]. Neighborhoods change over time and an individual may move several times in life [22]. Wiles et al. (2009) conducted a qualitative study that led to the definition of the "social space", capturing the "elastic physical, imaginative, emotional and symbolic experiences of and connections to people and place across time and in scope" [114]. Moreover, the association between the built environment and personal characteristics may have a dynamic interaction that has not been thoroughly explored [92]. It is important to take into account different levels (housing, neighborhood, transportation] since bias could occur as a result of focusing on a spe- cific level $[113,115]$. However, in some health domains (e.g. health and thermal insulation) only one level may suitable. Confounding factors (age, education, managing stress, health behaviors, religious coping, financial status, etc), which might be responsible for some of the results, should also be assessed [22, 112].

Our review has limitations. Age selection aimed to select participants over 50 years following a similar approach in other papers and reviews on this topic, but there are reviews which take 60-65 years of age as a reference, which could affect the final interpretation $[72,116]$. Separately, the latter stages of the life are linked to declining health, financial deprivation and social isolation [22]. This situation differs among countries and hampers extrapolation. Moreover, there has been a lack of standardized terminology regarding the built environment for years and most studies have adapted their own type of measurements so that similar variables may not imply similar approach, and a different implication for health. Some efforts have been made in recent years to summarize them, such as the Healthy Places Terminology Directory of the CDC and the European Environment Information and Observation Network's Thesaurus [117, 118]. Articles including populations living in institutions or any housing for the elderly (e.g. retirement community) were excluded as these are special populations living in adapted communities with special care. It would be interesting to assess these groups to detect any possible association that could lead to fostering the best health policies for them. Finally, the purpose of this review was to provide a comprehensive synthesis of the evidence on the built environment and health in the elderly, but in order to identify clear patterns of association meta-analysis would be needed.

\section{CONCLUSION}

Although with some methodological limitations, the evidence reviewed in this paper suggests that some builtenvironment variables may impact on health, especially in some specific issues. There is need for further investigation to clarifying this relationship, and this should be achieved through large samples using longitudinal studies. These should consider different level environment domains through similar frameworks including objective and subjective validated evaluations to enable reliability and comparability within and among them. Furthermore, the identification of clear associations between health and built environment could have a beneficial impact on future public policy making.

\section{CONFLICT OF INTEREST}

The authors confirm that this article content has no conflict of interest.

\section{ACKNOWLEDGEMENTS}

The research leading to these results has received funding from the European Community's Seventh Framework Programme (FP7/2007-2013) under grant agreement number 223071 (COURAGE in Europe) and the Spanish Ministry of Education, Culture and Sport (FPU12/05661). Additional support was provided by funds from the Instituto de Salud 
Carlos III-FIS research grants number PS09/00295 and PS09/01845, from the Spanish Ministry of Science and Innovation's ACI-Promociona (ACI2009-1010) and the Fundació Recercaixa (An age-friendly city for a successful ageing project). This article is part of a PhD programme developed in the Public Health Department of the Universitat de Barcelona, Spain.

\section{REFERENCES}

[1] United Nations. Population ageing and Development 2012. Dep. Econ. Soc. Aff. Popul. Div. New York. New York; 2012; 1-2. Available at: http://www.un.org/esa/population/publications/2012 PopAgeingDev_Chart/2012PopAgeingandDev_WallChart.pdf

[2] Sundararajan V, Henderson T, Perry C, et al. New ICD-10 version of the Charlson comorbidity index predicted in-hospital mortality. J Clin Epidemiol 2004; 57(12): 1288-94.

[3] Merikangas KR, Ames M, Cui L, et al. The impact of comorbidity of mental and physical conditions on role disability in the US adult household population. Arch Gen Psychiatry 2007; 64(10): 1180-8.

[4] Lehnert $\mathrm{T}$, Heider $\mathrm{D}$, Leicht $\mathrm{H}$, et al. Review: health care utilization and costs of elderly persons with multiple chronic conditions. Med Care Res Rev 2011; 68(4): 387-420.

[5] Ose D, Miksch A, Urban E, et al. Health related quality of life and comorbidity. A descriptive analysis comparing EQ-5D dimensions of patients in the German disease management program for type 2 diabetes and patients in routine care. BMC Health Serv Res 2011; 11: 179 .

[6] Wong CY, Chaudhry SI, Desai MM, Krumholz HM. Trends in comorbidity, disability, and polypharmacy in heart failure. Am J Med 2011; 124(2): 136-43.

[7] Kirchberger I, Meisinger C, Heier M, et al. Patterns of multimorbidity in the aged population. Results from the KORAAge study. PLoS One 2012; 7(1): e30556.

[8] Nagl A, Witte J, Hodek JM, Greiner W. Relationship between multimorbidity and direct healthcare costs in an advanced elderly population. Results of the PRISCUS trial. Z Gerontol Geriatr 2012; 45(2): $146-54$

[9] Garin N, Olaya B, Perales J, et al. Multimorbidity patterns in a national representative sample of the Spanish adult population. PLoS One 2014; 9(1): e84794.

[10] European Commission. Taking forward the strategic implementation plan of the European innovation partnership on active and healthy ageing. Brussels, $\operatorname{COM}(2012) 83$ Final 29.2.2012. 2012. Available at: http://ec.europa.eu/ health/ageing/docs/com 201283 en.pdf

[11] World Health Organization. Knowledge translation on ageing and health. A framework for policy development 2012. WHO Doc Prod Serv. Geneva, Switzerland. 2012. Available at: http://www.who.int/ageing/publications/knowledge_translation_en. pdf

[12] World Health Organization. Active ageing: a policy framework. Geneva, Switzerland. World Health Organization; 2003; Available at: http://whqlibdoc.who.int/hq/2002/WHO_NMH_NPH_02.8.pdf

[13] The Swedish National Institute of Public Health. Healthy ageing: a challenge for Europe. NRS Tryckeri AB. Huskvarna, Sweden. 2007; R 2006(29).

[14] Clarke P, Ailshire JA, Bader M, et al. Mobility disability and the urban built environment. Am J Epidemiol 2008; 168(5): 506-13.

[15] Cunningham GO, Michael YL. Concepts guiding the study of the impact of the built environment on physical activity for older adults: a review of the literature. Am J Health Promot 2004; 18(6): 435-43.

[16] Stokols D. Establishing and maintaining healthy environments. Toward a social ecology of health promotion. Am Psychol 1992; 47(1): 6-22.

[17] Oswald F, Wahl H-W. Housing and health in later life. Rev Environ Health 2004; 19(3-4): 223-52.

[18] Tse T. The environment and falls prevention: Do environmental modifications make a difference? Aust Occup Ther J 2005; 52(4): 271-81.

[19] Stewart JE, Battersby SE, Lopez-De Fede A, et al. Diabetes and the socioeconomic and built environment: geovisualization of disease prevalence and potential contextual associations using ring maps. Int J Health Geogr 2011; 10: 18.

[20] Bind M-A, Baccarelli A, Zanobetti A, et al. Air pollution and markers of coagulation, inflammation, and endothelial function: associations and epigene-environment interactions in an elderly cohort. Epidemiology 2012; 23(2): 332-40.

[21] Carlson JA, Sallis JF, Conway TL, et al. Interactions between psychosocial and built environment factors in explaining older adults' physical activity. Prev Med (Baltim). 2012; 54(1): 68-73.

[22] Clarke P, Nieuwenhuijsen ER. Environments for healthy ageing: a critical review. Maturitas 2009; 64(1): 14-9.

[23] Macintyre S, Maciver S, Sooman A. Area, Class and health: should we be focusing on places or people? J Soc Policy 1993; 22(02): 213-34.

[24] Diez-Roux A V, Nieto FJ, Muntaner C, et al. Neighborhood environments and coronary heart disease: a multilevel analysis. Am J Epidemiol 1997; 146(1): 48-63.

[25] Humpel N, Owen N, Leslie E. Environmental factors associated with adults' participation in physical activity: a review. Am J Prev Med 2002; 22(3): 188-99.

[26] Evans GW, Wells NM, Moch A. Housing and mental health: a review of the evidence and a methodological and conceptual critique. J Soc Issues 2003; 59(3): 475-500.

[27] Joshu CE, Boehmer TK, Brownson RC, Ewing R. Personal, neighbourhood and urban factors associated with obesity in the United States. J Epidemiol Community Health 2008; 62(3): 202-8.

[28] Renalds A, Smith TH, Hale PJ. A systematic review of built environment and health. Fam Community Health 2010; 33(1): 68-78.

[29] Miranda ML, Messer LC, Kroeger GL. Associations between the quality of the residential built environment and pregnancy outcomes among women in North Carolina. Environ Health Perspect 2012; 120(3): 471-7.

[30] Araya R, Montgomery A, Rojas G, et al. Common mental disorders and the built environment in Santiago, Chile. Br J Psychiatry 2007; 190: 394-401.

[31] Perks T, Haan M. The dwelling-type choices of older Canadians and future housing demand: an investigation using the aging and Social Support Survey (GSS16). Can J Aging. 2010; 29(3): 445-63.

[32] Thomas H, Weaver N, Patterson J, et al. Mental health and quality of residential environment. Br J Psychiatry. 2007; 191: 500-5.

[33] Clarke PJ, Ailshire JA, Nieuwenhuijsen ER, de Kleijn-de Vrankrijker MW. Participation among adults with disability: the role of the urban environment. Soc Sci Med 2011; 72(10): 1674-84.

[34] Yen IH, Michael YL, Perdue L. Neighborhood environment in studies of health of older adults: a systematic review. Am J Prev Med 2009; 37(5): 455-63.

[35] Gebel K, Bauman AE, Petticrew M. The physical environment and physical activity: a critical appraisal of review articles. Am J Prev Med 2007; 32(5): 361-9.

[36] Camilloni L, Farchi S, Rossi PG, et al. A case-control study on risk factors of domestic accidents in an elderly population. Int $\mathrm{J}$ Inj Contr Saf Promot 2011; 18(4): 269-76.

[37] Chan WC, Law J, Seliske P. Bayesian spatial methods for smallarea injury analysis: a study of geographical variation of falls in older people in the Wellington-Dufferin-Guelph health region of Ontario, Canada. Inj Prev 2012; 18(5): 303-8.

[38] Dogan H, Canbaz S, Tander B, et al. The prevalence of home injuries among elderly people in Samsun, Turkey, and the influencing factors. TURKISH J Med Sci 2010; 40(4): 651-8.

[39] Evci ED, Ergin F, Beşer E. Home accidents in the elderly in Turkey. Tohoku J Exp Med 2006; 209(4): 291-301.

[40] Gill T, Taylor AW, Pengelly A. A population-based survey of factors relating to the prevalence of falls in older people. Gerontology 2005; 51(5): 340-5.

[41] Pluijm SMF, Smit JH, Tromp EAM, et al. A risk profile for identifying community-dwelling elderly with a high risk of recurrent falling: results of a 3-year prospective study. Osteoporos Int 2006; 17(3): 417-25.

[42] Huang T-T. Home environmental hazards among communitydwelling elderly persons in Taiwan. J Nurs Res 2005; 13(1): 49-57. Morris KS, McAuley E, Motl RW. Self-efficacy and environmental correlates of physical activity among older women and women with multiple sclerosis. Health Educ Res 2008; 23(4): 744-52.

[44] Iwarsson S. A long-term perspective on person-environment fit and ADL dependence among older Swedish adults. Gerontologist 2005; 45(3): 327-36. 
[45] Freedman VA, Grafova IB, Schoeni RF, Rogowski J. Neighborhoods and disability in later life. Soc Sci Med 2008; 66(11): 2253-67.

[46] Clarke P, Ailshire JA, Lantz P. Urban built environments and trajectories of mobility disability: Findings from a national sample of community-dwelling American adults (1986-2001). Soc Sci Med 2009; 69(6): 964-70.

[47] Balfour JL, Kaplan GA. Neighborhood environment and loss of physical function in older adults: evidence from the Alameda County Study. Am J Epidemiol 2002; 155(6): 507-15.

[48] Clarke P, George LK. The role of the built environment in the disablement process. Am. J. Public Health 2005; 95(11): 1933-9.

[49] Breeze E, Mangtani P, Fletcher AE, et al. Trends in influenza vaccination uptake among people aged over 74 years, 1997-2000: survey of 73 general practices in Britain. BMC Fam Pract 2004; 5:

[50] Lang IA, Gibbs SJ, Steel N, Melzer D. Neighbourhood deprivation and dental service use: a cross-sectional analysis of older people in England. J. Public Health (Oxf) 2008; 30(4): 472-8.

[51] Takano $T$, Nakamura $K$, Watanabe $M$. Urban residential environments and senior citizens' longevity in megacity areas: the importance of walkable green spaces. J. Epidemiol Community Health. 2002; 56(12): 913-8.

[52] Zuluaga MC, Guallar-Castillon $\mathrm{P}$, Conthe $\mathrm{P}$, et al. Housing conditions and mortality in older patients hospitalized for heart failure. Am Heart J 2011; 161(5): 950-5.

[53] Vandentorren S, Bretin P, Zeghnoun A, et al. August 2003 heat wave in France: risk factors for death of elderly people living at home. Eur J Public Health 2006;16(6): 583-91.

[54] Iwarsson S, Horstmann V, Slaug B. Housing matters in very old age - yet differently due to ADL dependence level differences. Scand J Occup Ther 2007; 14(1): 3-15.

[55] Malhotra R, Chan A, Malhotra C, et al. Prevalence, awareness, treatment and control of hypertension in the elderly population of Singapore. Hypertens Res 2010; 33(12): 1223-31.

[56] Mishra V. Effect of indoor air pollution from biomass combustion on prevalence of asthma in the elderly. Environ Health Perspect 2003; 111(1): 71-8.

[57] Niemann H, Bonnefoy $\mathrm{X}$, Braubach $\mathrm{M}$, et al. Noise-induced annoyance and morbidity results from the pan-European LARES study. Noise Health 2006; 8(31): 63-79.

[58] Osman LM, Ayres JG, Garden C, et al. Home warmth and health status of COPD patients. Eur. J. Public Health. 2008; 18(4): 399-405.

[59] Osman LM, Ayres JG, Garden C, et al. A randomised trial of home energy efficiency improvement in the homes of elderly COPD patients. Eur Respir J 2010; 35(2): 303-9.

[60] Rudge J, Gilchrist R. Excess winter morbidity among older people at risk of cold homes: a population-based study in a London borough. J Public Health 2005; 27(4): 353-8.

[61] Singh N. Housing Environment on Morbid Conditions of the Elderly. J Hum Ecol 2012; 37(3): 159-66.

[62] Parra DC, Gomez LF, Sarmiento OL, et al. Perceived and objective neighborhood environment attributes and health related quality of life among the elderly in Bogotá, Colombia. Soc Sci Med 2010; 70(7): 1070-6.

[63] Werngren-Elgström M, Carlsson G, Iwarsson S. A 10-year followup study on subjective well-being and relationships to personenvironment (P-E) fit and activity of daily living (ADL) dependence of older Swedish adults. Arch Gerontol Geriatr 2009; 49(1): e16-22.

[64] Webb E, Blane D, de Vries R. Housing and respiratory health at older ages. J Epidemiol Community Health 2013; 67(3): 280-5.

[65] Wen M, Hawkley LC, Cacioppo JT. Objective and perceived neighborhood environment, individual SES and psychosocial factors, and self-rated health: an analysis of older adults in Cook County, Illinois. Soc Sci Med 2006; 63(10): 2575-90.

[66] Windle GS, Burholt V, Edwards RT. Housing related difficulties, housing tenure and variations in health status: evidence from older people in Wales. Health Place 2006; 12(3): 267-78.

[67] Wilson RT, Chase GA, Chrischilles EA, Wallace RB. Hip fracture risk among community-dwelling elderly people in the United States: a prospective study of physical, cognitive, and socioeconomic indicators. Am J Public Health 2006; 96(7): 1210-8.

[68] Satariano WA, Ivey SL, Kurtovich E, et al. Lower-body function, neighborhoods, and walking in an older population. Am J Prev Med 2010; 38(4): 419-28.
[69] Gómez LF, Parra DC, Buchner D, et al. Built environment attributes and walking patterns among the elderly population in Bogotá. Am J Prev Med 2010; 38(6): 592-9.

[70] Shores KA, West ST, Theriault DS, Davison EA. Extra-individual correlates of physical activity attainment in rural older adults. Rural Health 2009; 25(2): 211-8.

[71] Brown SC, Mason CA, Perrino T, et al. Built environment and physical functioning in Hispanic elders: the role of "eyes on the street". Environ Health Perspect 2008; 116(10): 1300-7.

[72] Rosso AL, Auchincloss AH, Michael YL. The urban built environment and mobility in older adults: a comprehensive review. J Aging Res 2011; 2011: 816106.

[73] Anderson M, Carmichael C, Murray V, et al. Defining indoor heat thresholds for health in the UK. Perspect Public Health 2013; 133(3): 158-64.

[74] Webber SC, Porter MM, Menec VH. Mobility in older adults: a comprehensive framework. Gerontologist 2010; 50(4): 443-50.

[75] Ritchie K, Artero S, Beluche I, et al. Prevalence of DSM-IV psychiatric disorder in the French elderly population. $\mathrm{Br} \mathrm{J}$ Psychiatry 2004; 184: 147-52

[76] Evans GW. The built environment and mental health. J Urban Health 2003; 80(4): 536-55.

[77] Vieira RT, Caixeta L, Machado S, et al. Epidemiology of earlyonset dementia: a review of the literature. Clin Pract Epidemiol Ment Health 2013; 9: 88-95.

[78] Howden-Chapman PL, Chandola T, Stafford M, Marmot M. The effect of housing on the mental health of older people: the impact of lifetime housing history in Whitehall II. BMC Public Health 2011; 11: 682 .

[79] Fonda SJ, Wallace RB, Herzog AR. Changes in driving patterns and worsening depressive symptoms among older adults. J Gerontol B Psychol Sci Soc Sci 2001; 56(6): S343-51.

[80] Chan A, Malhotra C, Malhotra R, Ostbye T. Living arrangements, social networks and depressive symptoms among older men and women in Singapore. Int J Geriatr Psychiatry 2011;26(6): 630-9.

[81] Lai DWL, Guo A. Gender differences in depressive symptoms of aging chinese in urban jiangsu in China. Clin Gerontol 2011; 34(3): 190-206.

[82] Saarloos D, Alfonso H, Giles-Corti B, et al. The built environment and depression in later life: the health in men study. Am J Geriatr Psychiatry 2011; 19(5): 461-70.

[83] Stewart R, Prince M, Harwood R, et al. Quality of accommodation and risk of depression in later life: an analysis of prospective data from the Gospel Oak Project. Int J Geriatr Psychiatry 2002; 17(12): 1091-8.

[84] Berke EM, Gottlieb LM, Moudon AV, Larson EB. Protective association between neighborhood walkability and depression in older men. J Am Geriatr Soc 2007; 55(4): 526-33.

[85] Evans GW, Kantrowitz E, Eshelman P. Housing quality and psychological well-being among the elderly population. J Gerontol B Psychol Sci Soc Sci 2002; 57(4): P381-3.

[86] Brown SC, Mason CA, Lombard JL, et al. The relationship of built environment to perceived social support and psychological distress in Hispanic elders: the role of "eyes on the street". J Gerontol B Psychol Sci Soc Sci 2009; 64(2): 234-46.

[87] Blazer DG. Depression in late life: review and commentary. J Gerontol A Biol Sci Med Sci 2003; 58(3): 249-65.

[88] Rimer J, Dwan K, Lawlor DA, et al. Exercise for depression. Cochrane database Syst Rev 2012; 7: CD004366.

[89] Mura G, Carta MG. Physical activity in depressed elderly. A systematic review. Clin Pract Epidemiol Ment Health 2013; 9: 12535.

[90] Lui C-W, Everingham J-A, Warburton J, et al. What makes a community age-friendly: A review of international literature. Australas J Ageing 2009; 28(3): 116-21.

[91] Sugiyama T, Thompson CW. Outdoor environments, activity and the well-being of older people: conceptualising environmental support. Environ Plan A 2007; 39(8): 1943-60.

[92] Menec VH, Means R, Keating N, et al. Conceptualizing agefriendly communities. Can J aging 2011;30(3): 479-93.

[93] World Health Organization. The World Health Organization Quality of Life Assessment (WHOQOL): development and general psychometric properties. Soc Sci Med 1998; 46(12): 1569-85.

[94] Diener E, Suh EM, Lucas RE, Smith HL. Subjective well-being: Three decades of progress. Psychol Bull 1999; 125(2): 276-302. 
[95] World Health Organization. Global Age-friendly Cities: A Guide. WHO, editor. Community Health (Bristol). WHO; 2007; 77. Available at: http://www.who.int/ageing/publications/ Global_age_friendly_cities_Guide_English.pdf

[96] Oswald F, Wahl H-W, Schilling $\mathrm{O}$, et al. Relationships between housing and healthy aging in very old age. Gerontologist 2007; 47(1): 96-107.

[97] Oswald F, Jopp D, Rott C, Wahl H-W. Is aging in place a resource for or risk to life satisfaction? Gerontologist 2011; 51(2): 238-50.

[98] Ng TP, Broekman BFP, Niti M, et al. Determinants of successful aging using a multidimensional definition among Chinese elderly in Singapore. Am J Geriatr Psychiatry 2009; 17(5): 407-16.

[99] Phillips DR, Siu OL, Yeh AGO, Cheng KHC. The impacts of dwelling conditions on older persons' psychological well-being in Hong Kong: the mediating role of residential satisfaction. Soc Sci Med 2005; 60(12): 2785-97.

[100] Oswald F, Wahl HW, Mollenkopf H, Schilling O. Housing and life satisfaction of older adults in two rural regions in Germany. Res Aging 2003; 25(2): 122-43.

[101] Carta MG, Aguglia E, Caraci F, et al. Quality of life and urban / rural living: preliminary results of a community survey in Italy. Clin Pract Epidemiol Ment Health 2012; 8: 169-74.

[102] Raudenbush SW, Sampson RJ. Ecometrics: toward a science of assessing ecological settings, with application to the systematic social observation of neighborhoods. Sociol Methodol 1999; 29(1): $1-41$.

[103] Frank LD, Schmid TL, Sallis JF, et al. Linking objectively measured physical activity with objectively measured urban form: findings from SMARTRAQ. Am J Prev Med 2005; 28(2 Suppl 2): $117-25$.

[104] Saelens BE, Sallis JF, Black JB, Chen D. Neighborhood-based differences in physical activity: an environment scale evaluation. Am J Public Health 2003; 93(9): 1552-8.

[105] Cerin E, Saelens BE, Sallis JF, Frank LD. Neighborhood environment walkability scale: validity and development of a short form. Med Sci Sports Exerc 2006; 38(9): 1682-91.

[106] Leslie E, Saelens B, Frank L, et al. Residents' perceptions of walkability attributes in objectively different neighbourhoods: a pilot study. Health Place 2005; 11(3): 227-36.
[107] Fänge A, Iwarsson S. Accessibility and usability in housing: construct validity and implications for research and practice. Disabil Rehabil 2003; 25(23): 1316-25.

[108] Iwarsson S, Nygren C, Slaug B. Cross-national and multiprofessional inter-rater reliability of the Housing Enabler. Scand J Occup Ther 2005; 12(1): 29-39.

[109] Slaug Enabling Development V\& SH. The Enabler web site Providing tools for professional assessments of accesibility problems in the environment 2012 Available at: http://www.enabler.nu/

[110] Openshaw S. The modifiable areal unit problem. Norwich: Geo Books; 1984.

[111] Erkilic M. Conceptual challenges between universal design and disability in relation to the body, impairment, and the environment. METU J Fac Archit 2011; 28(2): 181-203.

[112] Hunter RH, Sykes K, Lowman SG, et al. Environmental and policy change to support healthy aging. J Aging Soc Policy 2011; 23(4): 354-71.

[113] Kerr J, Rosenberg D, Frank L. The role of the built environment in healthy aging: community design, physical activity, and health among older adults. J Plan Lit 2012; 27(1): 43-60.

[114] Wiles JL, Allen RES, Palmer AJ, et al. Older people and their social spaces: a study of well-being and attachment to place in Aotearoa New Zealand. Soc Sci Med 2009; 68(4): 664-71.

[115] Li F, Fisher KJ, Brownson RC, Bosworth M. Multilevel modelling of built environment characteristics related to neighbourhood walking activity in older adults. J Epidemiol Community Health 2005; 59(7): 558-64

[116] Wahl H-W, Fänge A, Oswald F, et al. The home environment and disability-related outcomes in aging individuals: what is the empirical evidence? Gerontologist 2009; 49(3): 355-67.

[117] Centers for Disease Control and Prevention. Healthy places terminology 2010 Available at: http://www.cdc.gov/healthyplaces/ terminology.htm

[118] EIONET. European Environment Information and Observation Network 2012. Available at: http://www.eionet.europa.eu/

(C) Garin et al.; Licensee Bentham Open.

This is an open access article licensed under the terms of the Creative Commons Attribution Non-Commercial License (http://creativecommons.org/licenses/by-nc/3.0/) which permits unrestricted, non-commercial use, distribution and reproduction in any medium, provided the work is properly cited. 